\title{
Expressions of Propositional Modality in Japanese and Chinese
}

\author{
Xiangdong Liu \\ School of Humanities and Communication Arts, University of Western Sydney, Sydney, Australia \\ Email: x.liu@uws.edu.au
}

Received 25 October 2013; revised 2 December 2013; accepted 12 December 2013

Copyright (C) 2014 by author and Scientific Research Publishing Inc.

This work is licensed under the Creative Commons Attribution International License (CC BY). http://creativecommons.org/licenses/by/4.0/

c. (i) Open Access

\begin{abstract}
This study investigates expressions of propositional modality (epistemic and evidential) in Japanese and Chinese. It aims to highlight some fundamental characteristics of and differences between the modal systems in the two languages. It has been found that adverbs in Chinese play a more important role than adverbs in Japanese in expressing modal meanings. This study has also found that more modal expressions are used in the Japanese text than in the Chinese translations. That is to say, Chinese language speakers seem to prefer straightforward assertions to marked epistemic forms. In other words, Chinese speakers often choose realis modality when describing things, situations or their own ideas, unless the speaker thinks it is very necessary to clearly indicate that the proposition is not an absolute fact, or has not been confirmed to be a truth. Data of this study are collected from a Japanese-Chinese bilingual corpus, and the discussion is based on a concept of realis/irrealis.
\end{abstract}

\section{Keywords}

Epistemic Modality; Evidential Modality; Japanese; Chinese; Noda

\section{Introduction}

Modality is a complicated linguistic issue. Questions including “What is modality?”, "How is it recognized?” and "What should be considered modal devices or expressions?" have been discussed over the last decades. Despite a great amount of attempts in finding answers to these questions, there has not been a consensus among researchers. In addition, although theories and claims about modality developed on the basis of studies on English provide a wealth of information on studies on other languages, fundamental differences between languages in terms of typology have determined that findings in one language may not be plausible when dealing with another. It is therefore not surprising that modality is a difficult aspect for translators to deal with, for language in- 
structors to teach and for language learners to acquire, especially when the language pair of a learner has different modal systems and when modal devices do not map neatly from one language to the other. For instance, some modal devices may be recognised morphologically or grammatical patterns in one language of the pair being compared in this paper (e.g. Japanese) but appear as free-standing words in the other (e.g. Chinese).

This paper investigates modal expressions in Japanese and Chinese with a focus on propositional (i.e. epistemic and evidential) modality by comparing the usages of modal expressions observed in a Japanese novel (Kokoro by Ntsume Soseki) and modal expressions used in its Chinese translations by two different translators. Both the original text and the translations are included in the Chinese and Japanese Bilingual Corpus (Beijing Centre for Japanese Studies, 2003). By investigating the modal expressions observed in the Japanese source text and its Chinese translations, this paper aims to highlight some fundamental characteristics of and differences between the modal systems of the two languages, and to provide some hints for the understanding, teaching and learning of the two languages.

In the following sections, we will first clarify the definition of modality that the current study adopts and identify some main issues in studies of modality in the two languages in Section 2, and then present findings in Section 3. In Section 4, we will discuss what the findings suggest, followed by the conclusion in Section 5.

\section{Definition, Subcategories and Devices of Modality}

Before discussing data and findings, it is necessary to first establish a basic understanding of the notion "modality” and its subdomains.

The conceptual category "modality" has been given various definitions and described with different sets of terms by researchers. By the term "modality", this study refers to a general concept held by many researchers: the opinion or attitude of the speaker or the writer towards the proposition or towards the situation that the proposition describes (Lyons, 1977: p. 452; Frawley, 1992: p. 386; Halliday, 1994: pp. 75,89; etc.). This definition of modality has been commonly adopted by many Japanese (e.g. Teramura, 1978: p. 97; Johnson, 1999: p. 146; Miyazaki et al., 2002: p. 2; etc.) and Chinese (e.g. Li, 2004; Hsieh, 2009: p. 2; etc.) scholars.

The taxonomy of modality also varies across studies. There have been several suggestions regarding subcategories of modality. Among them, Lyons identified two main types: epistemic modality and deontic modality (Lyons, 1977), Frawley claimed three: negative modality, epistemic modality and deontic modality (Frawley, 1992: pp. 384-390), and Palmer suggested that the modal system is composed of four main types: epistemic modality, evidential modality, deontic modality and dynamic modality (Palmer, 2001). According to Palmer, the first two types (i.e. epistemic and evidential modality) are "propositional modality” and the third and forth types (i.e. deontic and dynamic modality) are "event modality”. In spite of the differences in labeling the subcategories of modality, the early literature share a common view, that is, epistemic modality and deontic modality are two important components that cannot be neglected when discussing modality, and epistemic modality is about possibility and degrees of certainty, while deontic modality deals with necessity, obligation, and ability. This study adopts Palmer's classification and terminology, as his four subclasses elucidate the functions of modal expressions more clearly and precisely, and as they are more helpful when investigating modal devices in the Japanese language. In fact, this “four-category system” (called yonbun-hoo in Japanese) has attracted greater attention of Japanese linguists in the recent years, and been applied in several latest works (e.g. Tamaji, 2005; Arita, 2009; Narrog, 2009). Palmer's classification and description for each subcategory are summarized Table 1.

The intricacy of modality leads to not only various definitions and classifications introduced above, but also different views regarding what should be considered as entries in the inventories of expressions encoding modality. Those define modality in a narrow sense assert that modality are recognized by modal auxiliaries, while others include in their lists of modal devices a wider range of expressions conveying modal meanings such as modal verbs, adverbs, auxiliary verbs, inflection, affixes, particles, adjectives and nouns. Some also claim that modality can also be expressed by intonation in a spoken discourse (e.g. Saji, 1999: p. 80; Li, 2004: p. 2). This

Table 1. Palmer's classification of modality.

\begin{tabular}{|c|c|c|}
\hline \multirow{2}{*}{ Modality } & Propositional modality & $\begin{array}{l}\text { a. Epistemic modality: speakers express their judgments about the factual states of the proposition } \\
\text { b. Evidential modality: speakers indicate the evidence they have for its factual status }\end{array}$ \\
\hline & Event modality & $\begin{array}{l}\text { c. Deontic modality: the conditioning factors are external to the relevant individual } \\
\text { d. Dynamic modality: the conditioning factors are internal to the relevant individual }\end{array}$ \\
\hline
\end{tabular}


study maintains that the broader view applies in principle to Japanese and Chinese, but needs some minor modifications. That is, firstly, modal meanings in Japanese are sometimes expressed by grammatical patterns, or combinations of two or more items claimed above; and secondly, Chinese is not an inflected language and therefore inflection does not exist in its list of modal expressions. Table 2 shows some examples of modal markers in Japanese and Chinese mentioned in previous studies as indicated in the last row of the table. The grammatical property of each group of expressions is given in the parentheses.

As mentioned earlier, this study focuses on propositional modal expressions and discusses the uses of these expressions in Japanese and Chinese.

\section{Data and Findings}

\subsection{Data Sources for This Study}

As mentioned briefly earlier, the data set for the current study includes Kokoro by Natsume Soseki (Natsume, 1904), a Japanese novel, and its Chinese translations by two different translators-Dong (1982) and Zhou (1983). This data set is chosen because the current comparative study of modal expressions across languages aims to investigate how speakers or writers of the two languages in question get across a particular attitude or opinion in a particular situation, and what modal expression/s they use. A bilingual corpus is no doubt a good vehicle for this type of studies. When using translations as data, however, we need to keep in mind that language use in a translation is determined simultaneously by multiple factors, some of which could be personal and subjective. In order to carefully ensure the quality and objectivity of data, the current study chooses Kokoro as the Japanese source text for there are two translations in the corpus. The two translations are referred to as "TA" (i.e. Translation A) and "TB" (i.e. Translation B) respectively hereafter.

The novel Kokoro is published in 1914, almost one hundred year ago, but the closed class of the language has not changed much since then, although some differences from today's Japanese are evident at the level of vocabulary including uses of Kanji characters. Therefore, it is still a suitable data source for studies on modal expressions. On the other hand, the two Chinese translations are published in 1982 and 1983 respectively, and reflect the present state of modal expressions in the Chinese language.

Table 2. Examples of modal devices in Japanese and Chinese.

\begin{tabular}{|c|c|c|c|}
\hline Type of modality & & Japanese & Chinese $^{a}$ \\
\hline \multirow[t]{3}{*}{$\begin{array}{l}\text { Propositional } \\
\text { modality }\end{array}$} & Epistemic modality & $\begin{array}{l}\text { daroo (conjectural form of the copula), } \\
\text { kamoshirenai, nichigainai, (grammatical patterns) } \\
\text { hazuda, wakeda, noda, (auxiliaries) } \\
\text { omou (verb) } \\
\text { osoraku, tabun (adverbs) } \\
\text { yo, ne (sentence final particles) }\end{array}$ & $\begin{array}{l}\text { xiangxin (verb) } \\
\text { yexu (adverb) } \\
\text { ba (particle) }\end{array}$ \\
\hline & Evidential modality & yooda, rashii, sooda (auxiliaries) & sihu, haoxiang (adverbs) \\
\hline & Deontic modality & $\begin{array}{l}\text { bekida, (auxiliaries) } \\
\text { nakerebanaranai, temo ii (grammatical patterns) }\end{array}$ & $\begin{array}{l}\text { neng, keyi, yinggai (modal verb }{ }^{\mathrm{c}} \text { ) } \\
\text { bixu (adverb) }\end{array}$ \\
\hline \multirow[t]{2}{*}{ Event modality } & Dynamic modality & $\begin{array}{l}\text { u, yoo (inflectional suffixes) } \\
\text { tai (auxiliary) } \\
\text { (ra) reru (auxiliary) } \\
\text { dekiru (verb, suffix) } \\
\text { koto ga dekiru (grammatical pattern) }\end{array}$ & $\begin{array}{l}\text { yao, xiang (modal verb) } \\
\text { yuanyi (verb) } \\
\text { keyi, hui }\end{array}$ \\
\hline & References & $\begin{array}{l}\text { (Teramura, 1984; Saji, 1999: pp. 80-81; Masuoka, 2002: pp. } \\
\text { 13-14; Kurotaki, 2005; Tamaji, 2005; Shirakawa, 2006) }\end{array}$ & (Zhu, 1996; Li, 2004; Hsieh, 2009) \\
\hline
\end{tabular}

${ }^{\mathrm{a}}$ It needs to be mentioned that studies in Chinese modality have not been as advanced as that of English and Japanese. Many issues remain unsolved including taxonomy of modality in Chinese. Researchers are far from reaching a consensus of descriptions regarding modal devices. Epistemic modality and evidential modality are not delimited in many previous investigations (e.g. Zhu, 1996; Hsieh, 2009). In fact, as noted in some literature, researchers hold different views about whether these two subcategories observed in many other languages are grammaticalised formally in a similar way in Chinese (Hsieh, 2009). This study makes a distinction between the two based on the meanings of each example in the data, for the sake of convenience in comparing with Japanese language; ${ }^{\mathrm{b}}$ There are different views in regarding part of speech of expressions of this kind. While some researchers regard this group as a kind of auxiliary (e.g. Teramura, 1984; Liu, 2008), some others call this group "quasi-auxiliaries” to differentiate them from auxiliaries which also function as verbal inflection affixes such as $u$, yoo, ta etc. (e.g. Saji, 1999). There is also another view claiming that these expressions are combinations consisting of a nominaliser (i.e. hazu, wake, no) and the copula da (e.g. Noda, 1997); ${ }^{\mathrm{C}}$ In Chinese language studies, different terms (e.g. "modal verb”, "modal auxiliary”, "nengyuan (“ability-wish”) verb”) have been used to refer to modal expressions that can precede the main verb in a sentence (e.g. neng (can), xiang (willing), bixu (must)). This study uses the term "auxiliary" when making mention to this group, in order to keep consistence with the terms used in Japanese studies. 


\subsection{Findings}

Modal expressions of epistemic and evidential modality observed in the Japanese novel and in the Chinese translations are summarized in Table 3. The symbol " $\varnothing$ " in Table 3 indicates cases where a model expression is observed in the Japanese source text but not in the Chinese translations, while the "!" signifies that some Japanese modal expressions are missing in their Chinese translations and an exclamation mark “!” is used instead. That is, some marked modal meanings in the Japanese source text are rendered into unmarked ones or omitted in the Chinese translations. As Table 3 shows, the symbol “ $\varnothing$ ” does not apply to the first three Japanese modal expressions on the list (i.e. suru sooda (hearsay), nichigainai ("must [be]"), and kamoshirenai ("may [be]")). In other words, every occurrence of these three modal forms observed in the data is translated into one of the Chinese modal expressions listed next to them, while the other forms on the list have some examples rendered into Chinese without any modal expression. The total number of examples of each Japanese modal expression observed in the data set and the numbers of examples translated into or without a Chinese modal are presented in Table 4.

\section{Discussion}

Recalling Table 1, one can see that adverbs in Chinese play a leading role in expressing modal meanings together with the modal auxiliaries, while adverbs in Japanese are not as visible as their Chinese counterparts. Below is one example.

1) Source text:

Kooiu kanji o sensei ni taishite motte ita mono wa ... watashi dake kamoshirenai.

TA:

$\underline{Y e x u} . .$. dui xiansheng you zhezhong ganjue de zhiyou wo ba.

(Maybe I am the only one who has this kind of feelings about the professor.)

In the above example, a grammatical pattern kamoshirenai ("maybe") is used in the Japanese source text, while an adverb yexu ("maybe, perhaps") is used in the Chinese translation.

Now let us discuss Tables 3 and 4, which show that many Japanese modal meanings are omitted or changed to an unmarked one in the Chinese translations. This could be interpreted as that modal meanings in Chinese are quite often implied in the context or expressed by intonation when speaking or by the exclamation mark "!” in written texts. This may also suggests that speakers of Chinese language prefer assertive forms to epistemic modal forms. Further investigations are needed to clarify this issue.

While using less modal expressions than the Japanese source text seems to be a common tendency shared by both TA and TB, the two translations present slight difference in terms of frequency of using modal expressions. As one can see from Table 4, more modal expressions have been observed in TB than in TA. However, this difference does not affect the objectivity and reliability of this study. The figures in Table 4 have revealed some meaningful points in regard to how the modal expressions in Japanese and Chinese correspond to and differ from one another.

Table 3. Modal expressions observed in the data.

\begin{tabular}{|c|c|}
\hline Modal expressions in the Japanese source text & Modal expressions in the Chinese translations \\
\hline suru sooda (hearsay) & jushuo, ... shuo \\
\hline nichigainai (“must [be]”) & zhun (ding), yiding (hui), hui, biding, biran, guran, dangran \\
\hline kamoshirenai (“may [be]”) & уехu, huoxu, shuobuding, kongpa, you keneng, ... ba \\
\hline rashii (“look like, seem, appear”) & (hao) xiang (shi), sihu, fangfu (... side), kanyangzi, dayue, ø \\
\hline yoo da (“look like, seem, appear”) & (hao) xiang (shi), sihu, fangfu, ø \\
\hline (shi) sooda (“look like, seem, appear”) & haoxiang, sihu, ... side, kanyangzi, ø \\
\hline $\begin{array}{c}\text { (osoraku/ookata/sazo/kitto) ...daroo } \\
\text { ("probably/must [be]” ... conjectural auxiliary) }\end{array}$ & $\begin{array}{c}\text { (kongpa/dayue/dagai/yiding) ... ba, shuobuding, } \\
\text { yexu, keneng, hui, wo xiang, ø }\end{array}$ \\
\hline ne (sentence final particle)/yo (sentence final particle) & ma, ya, a, la, ba, ne, !, ø/a ma, ba, bei, na, lou, ne, ø \\
\hline noda (“may [be]”) wakeda (“may [be]”) & shi $(\ldots$ de $), \ldots$ de, $a$, ya, na, la, ne, zhen ..., !, ø ziran, ø \\
\hline
\end{tabular}


Table 4. Summary of the examples in the data set.

\begin{tabular}{|c|c|c|c|c|c|c|}
\hline Modal expressions in Japanese & $\begin{array}{l}\text { Total umber } \\
\text { of examples }\end{array}$ & $\begin{array}{l}\text { Modals used } \\
\text { in both TA } \\
\text { and TB }\end{array}$ & $\begin{array}{l}\text { No modal } \\
\text { expression } \\
\text { in TA }\end{array}$ & $\begin{array}{l}\text { No modal } \\
\text { expression } \\
\text { in TB }\end{array}$ & $\begin{array}{c}\text { No modals } \\
\text { in both TA } \\
\text { and TB }\end{array}$ & Others $^{\mathrm{a}}$ \\
\hline suru sooda (hearsay) & 3 & 3 & - & - & - & - \\
\hline nichigainai (“must [be]”) & 7 & 7 & - & - & - & - \\
\hline Kamoshirenai ("may [be]”) & 17 & 17 & - & - & - & - \\
\hline Rashii (“look like, seem, appear”) & 19 & 14 & 3 & 1 & 1 & - \\
\hline Yooda (“look like, seem, appear”) & 17 & 11 & 3 & - & 2 & - \\
\hline (shi) sooda ("look like, seem, appear") & 6 & 2 & 2 & - & 1 & 1 \\
\hline $\begin{array}{c}\text { (osoraku/ookata/sazo/kitto) ... daroo } \\
\text { ("probably/must [be]" ... conjectural auxiliary) }\end{array}$ & 102 & 59 & 28 & 3 & 11 & 1 \\
\hline ne (sentence final particle) & 61 & 18 & 7 & 7 & 28 & 1 \\
\hline yo (sentence final particle) & 94 & 30 & 26 & 10 & 28 & - \\
\hline noda (“may [be]”) & 469 & 63 & 43 & 42 & 298 & 23 \\
\hline wakeda ("may [be]”) & 6 & 1 & - & 1 & - & - \\
\hline
\end{tabular}

${ }^{a}$ Examples in this group include those being omitted, mistranslated or translated freely in both TA and TB. In the case of noda, this group also includes translations which do not contain a modal expression equivalent to the one occurred in the source text but there is a non-modal word serving to convey the entire message of the source sentence.

\subsection{Degree of Possibility and Certainty}

It is interesting that the first three modal expressions in the tables (i.e. suru sooda (hearsay), nichigainai ("must [be]") and kamoshirenai ("may [be]")) have the best chance to be translated into an equivalent or closest modal expression in Chinese. It is also interesting that the next three items in the list rashii, yooda and (shi) sooda, which share the same meaning "look like, seem, appear", have shown differences in term of chances to be translated in to a modal expression in Chinese. To be precise, while 14 out of $19(73.7 \%)$ of the examples of rashii are translated into a Chinese modal expression, the ratios for yooda and (shi) sooda are 11 out of 17 (64.7\%) and 2 out of $6(33.3 \%)$ respectively.

As mentioned earlier, propositional modality is dealing with possibility and certainty. According to Johnson (1999), if we draw a coordinate curve showing the degrees of possibility and certainty, and place the modal expressions being discussed on the curve in order of degrees of possibility and certainty, then nichigainai ("must [be]") will be on the top indicating the strongest certainty and possibility, while kamoshirenai ("may [be]") will come to the bottom (Johnson, 1999).

Johnson did not discuss suru sooda (hearsay), but it is clear that, when a speaker/writer uses suru sooda to pass on information to their hearers/readers, they convey a strong degree of certainty and possibility, as what they are saying is what they have actually heard or read. For this reason, suru sooda should be on the top next to nichigainai, if we add it to the curve. This suggests that Japanese modal expressions conveying the strongest and the weakest degree of probability and certainty are most likely to have a Chinese modal expression in the translation.

Johnson (1999) also discussed rashii, yooda and (shi) sooda ("look like, seem, appear"), and placed yooda at a position second to nichigainai, the highest on the curve, followed by rashii and then (shi) sooda. Taking into account the cases of the three expressions discussed in the previous paragraphs, one of the reasons for the relatively lower chances for rashii, yooda and (shi) sooda to have a modal expression in their Chinese translations could be that they do not carry the strongest or lowest probability and certainty.

\subsection{Noda}

Another set of figures we must not overlook is that of noda. As shown in Table 4, as many as 469 examples were observed in the Japanese novel examined. This figure is much larger than any of the other expressions being discussed, and confirms that noda is one of the most (if not the most) widely used modal devices in Japanese. It also needs to be noticed that only 63 out of the 469 examples (i.e. 13.4\%) of noda are translated into a Chinese modal expression in both TA and TB. This marks the lowest percentage among the modal forms in Table 4. On 
the other hand, as many as 298 (63.5\%) out of the 469 examples of noda do not have a modal expression in either TA or TB. This is the highest among the expressions listed in the same table. This pair of the lowest and the highest figures indicates that noda is a unique construction in Japanese, and that it is used in quite different ways from the shi ... de construction in Chinese, although the two show some syntactic and semantic similarities.

Innumerable previous studies have attempted to describe and categorize the multiple functions and meanings of noda. By investigating how this expression is translated into Chinese, the current study claims two basic usages of noda: a) providing further information regarding venue, reason, means, connotation, etc. about something that has been mentioned in the context or is already known to listeners/readers; and b) providing some information completely new to listeners/readers with a strong appealing attitude (Liu, 2008). When providing further information, noda can be translated into the shi ... de construction in Chinese. On the other hand, when disclosing new information with a strong appealing tone, translations in Chinese are either unmarked or marked by a sentence final particle, such as $a, y a$, la, etc., or/and the exclamation mark “!”. Adverb "zhen...!” ("really...!”) has also been observed in the data several times. Below are two examples.

2) Source Text:

Watashi wa ... to iu uwasa o kikimashita. Watashi wa sono uwasa o mukashi chuugaku no dookyuusei deatta aru tomodachi kara kiita nodesu.

TB:

Wo tingdao yige fengsheng, shuo.... Na shi cong wo zhongxue tongxue de pengyou nali ting lai de.

(I've heard a rumour that... I heard this rumour from a friend who was a classmate of mine at junior high school.)

3) Source text

Shikashi ki o tsukenai to ikenai. Koi wa zaiaku na nda kara.

TB:

Keshi, bu jinshen buxing, aiqing shi zuie ya.

(But we have to be careful. Falling in love is a sin.)

In example (2), (watashi wa ... uwasa o) kiita ("I ... heard a rumour") is mentioned twice. After being uttered in the first sentence, it is repeated in the second with some additional information about how the speaker "heard the rumour" (i.e. "heard from a friend ..."). The repeated words in both the source and the translated texts are marked with a wave line, and noda and its Chinese counterpart, the shi ... de construction, are underlined.

Example (3), on the other hand, involves nda, a colloquial variety of noda. The function of noda in this example is to draw attention of the listener to the proposition koi wa zaiaku (da) ("falling in love is a sin"). The appealing tone is recognized in TB by the sentence final particle $y a$ rather than a modal auxiliary.

It needs to be pointed out that noda also has a cohesive function to relate the sentence in which it occurs to the rest of the text retrospectively or prospectively (Liu, 2008). The cohesive function and the two basic semantic and pragmatic functions discussed above are performed simultaneously. Apart from the shi ... de construction demonstrated in example (2), unmarked examples and examples involving an adverb jiu/bian/cai ("then, in that case") or a conjunction yinwei ("because") have also been noticed as illustrated in (4).

4) Source text

Watashi wa kono K to kodomo no toki kara no nakayoshi deshita. ... Futari ni wa dookyoo no enko ga atta nodesu.

TA:

Wo tong zhewei K, congxiao jiu hen yaohao. ... yinwei women shi tongxiang.

(I have been on good terms with $\mathrm{K}$ from childhood. ... Because we are from the same village.)

In example (4), the sentence ending with nodesu, a polite form of noda, provides further information about what has been said earlier, i.e. watashi wa kono K to kodomo no toki kara no nakayoshi deshita ("I have been on good terms with $\mathrm{K}$ from childhood”). The relation between the sentence ending with noda and the preceding one is indicated by the modal expression noda. Although the shi ... de construction in Chinese has the same function of explaining reasons for what has been mentioned earlier, TA decided to choose the conjunction yinwei ("because"), instead of shi ... de (the so-called noda in Chinese) to reflect the cohesive relation between the sentences and the logical relation between the two propositions- "being on good terms from childhood" and "coming from the same village".

The use and functions of epistemic modal device noda and some major strategies observed in the data for translating them into Chinese are summarized in Table 5. 
Table 5. Epistemic noda and translation strategies observed in data.

\begin{tabular}{cc}
\hline Functions of no da & $\begin{array}{c}\text { Expressions observed } \\
\text { in the Chinese translations }\end{array}$ \\
\hline Providing further information & Shi ... de, shi, ...de \\
yinwei \\
jiu, bian, cai, \\
Providing new information & $\emptyset$ \\
with appealing tone & $!$ \\
& $a$, ya, la, na \\
zhen...
\end{tabular}

\section{Conclusion}

This paper investigated the use of propositional modal auxiliaries in the Japanese novel Kokoro and compared them with the use of Chinese modal expressions in the translations. It has confirmed some meaningful characteristics of the modal systems in Japanese and Chinese. First of all, adverbs in Chinese play a more important role than adverbs in Japanese in expressing modal meanings. Secondly, more modal expressions are observed in the Japanese source text than in the Chinese translations. This may suggests that Chinese language speakers prefer assertive forms to epistemic or evidential forms. The use of modal expressions in the Chinese translations seems to relate to the degrees of certainty and probability that the Japanese modal expressions convey. Modal expressions with the strongest and the weakest degrees of certainty and possibility are more likely to have a modal expression in their Chinese translations. Based on the data examined, this study summarized a set of strategies for translating noda into Chinese. This can be applied to the teachings and learning of the two languages as a second language.

\section{References}

Arita, S. (2009). Tense and Settledness in Japanese Onditionals. In B. Pizziconi, \& M. Kizu (Eds.), Japanese Modality: Exploring Its Scope and Interpretation (pp. 117-149). Basingstoke: Palgrave Macmillan.

Beijing Center for Japanese Studies (2003). Chuu-Nichi Taiyaku Coopasu [Bilingual Chinese and Japanese Corpus].

Dong, X. C. (1982). Xin. Nanchang: Hunan People’s Publishing House (Translation A).

Frawley, W. (1992). Linguistic Semantics. Hillsdale, NJ: Laurence Erlbaum Associates, Publishers.

Halliday, M. A. K. (1994). An Introduction to Functional Grammar (2nd ed.). London: Arnold.

Hsieh, C.-L. (2009). Epistemic Stance Taking in Chinese Media Discourse. Lilun Yuyanxue Yanjiu (Electronic version), 3, 1-35.

Johnson, Y. (1999). Modariti Riron no Meikakuka o Motomete (A Novel Entrance to the Theory of Modality). In Y. S. Alam (Ed.), Gengogaku to Nihongo Kyooiku (Linguistics and Japanese Language Education) (pp. 145-160). Tokyo: Kurosio Publishers.

Kurotaki, M. (2005). Deontic Kara Epistemic e no Fuhensei to Sootaisei: Modariti no Nichi-Eigo Taishoo Kenkyuu. Tokyo: Kurosio Publishers.

Li, R. (2004). Modality in English and Chinese: A Typological Perspective. Boca Raton, FL: Dissertation.com.

Liu, X. (2008). The Discourse Functions of the Modal Auxiliaries "Wake Da" and "No Da" in Japanese. Munich: Lincom Europa Academic Publications.

Lyons, J. (1977). Semantics (Vol. 1 and 2). Cambridge, London, New York, Melbourne: Cambridge University Press.

Masuoka, T. (2002). Handan No Modality. Nihongogaku [Japanese Linguistics], 21, 6-16.

Miyazaki, K. et al. (2002). Modariti [Modality]. Tokyo: Kurosio.

Narrog, H. (2009). Modariti to Bun no Kaisoo Koozoo [Modality and Structure of Sentence]. Gengo [Language], 38, 34-41.

Natsume, S. (1904). Kokoro. In Beijing Center for Japanese Studies.

Palmer, F. R. (2001). Mood and Modality (2nd ed.). Cambridge, UK; New York: Cambridge University Press. http://dx.doi.org/10.1017/CBO9781139167178

Saji, K. (1999). Nihongo Gakushuusha ni Nihongo no Modariti o Doo Oshieru ka [How to Teach Modality in Japanese to Japanese Language Learners]. Gengo [Language], 28, 80-83. 
Shirakawa, H. (2006). Bunpoo II-Bun [Grammar II-Sentence]. In Y. Nuibe, \& S. Tawata (Eds.), Kooza Nihongo Kyooikugaku (Teaching Japanese as a Second Language) Vol. 6 Gengo no Taikei to Koozoo (pp. 50-68). Tokyo: 3A Network.

Tamaji, M. (2005). Nihongo to Chuugokugo no Modariti no Taishoo Kenkyuu: Gengo Ruikeiron no Kanten Kara (A Contrastive Study of Modality in Japanese and Chinese: A Linguistic Typological Perspective). Takamatsu Daigaku Kiyoo (Research Bulletin of Takamatsu University), 44, 17-54.

Teramura, H. (1978). Nihongo No Bunpoo [Japanese Grammar] (Vol. 1). Tokyo: Kokuritsu Kokugo Kenkyuujo.

Teramura, H. (1984). Nihongo No Shintakusu to Imi [Syntax and Semantics in Japanese] (Vol. 2). Tokyo: Kurosio Publishers.

Zhou, D. Y. (1983). Xin. Shanghai: Shanghai Translation Publishing House (Translation B).

Zhu, Y. (1996). Modality and Modulation in Chinese. In M. Berry, C. Butler, R. Fawcett, \& G. Huang (Eds.), Meaning and Form: Systemic Functional Interpretations (pp. 183-209). Norwood, NJ: Ablex Publishing Corporation. 